\title{
Comparative analysis of prevalence of intimate partner violence against women in military and civilian communities in Abuja, Nigeria
}

This article was published in the following Dove Press journal:

International Journal of Women's Health

10 March 2015

Number of times this article has been viewed

\section{Carol Uzoamaka Chimah' Prosper Obunikem Uche Adogu $^{2}$ Kofoworola Odeyemi ${ }^{3}$ Amobi Linus Ilika ${ }^{4}$}

'Medical Department, Ministry of Defence Headquarters, Abuja, Nigeria; ${ }^{2}$ Department of Community Medicine and PHC, Nnamdi Azikiwe University/ Nnamdi Azikiwe University Teaching Hospital, Nnewi, Nigeria; ${ }^{3}$ Department of Community Health, University of Lagos, Lagos, Nigeria
Correspondence: Prosper Obunikem Uche Adogu

Department of Community Medicine, Nnamdi Azikiwe University Teaching Hospital (NAUTH), Nnewi, Nigeria Tel +23480378I 7707

Email prosuperhealth@yahoo.com
Introduction: Intimate partner violence (IPV) occurs across the world, in various cultures, and affects people across societies irrespective of economic status or gender. Most data on IPV before World Health Organization multicountry study (WHOMCS) usually came from sources other than the military. Result of this study will contribute to the existing body of knowledge and may serve as a baseline for future studies in military populations. This study compares the prevalence of the different types of IPV against women in military and civilian communities in Abuja, Nigeria.

Methods: Using a multistage sampling technique, 260 women who had intimate male partners were selected from military and civilian communities of Abuja. Collected data on personal characteristics and different types of IPV experienced were analyzed to demonstrate comparison of the association between the different forms of IPV and the respondents' sociodemographic and partner characteristics in the two study populations using percentages and $\chi$-square statistics, and $P$-value was assumed to be significant at $\leq 0.05$.

Results: The prevalence of the four major types of IPV was higher among the military respondents than among civilians: controlling behavior, $37.1 \%$ versus $29.1 \%$; emotional/psychological abuse, $42.4 \%$ versus $13.4 \%$; physical abuse, $19.7 \%$ versus $5.9 \%$, and sexual abuse, $9.2 \%$ versus $8.8 \%$. Significantly more respondents from the military population (59 [45.4\%]) compared to civilians $(21[19.4 \%])$ were prevented by their partners from seeing their friends $(P=0.000)$. The situation is reversed with regard to permission to seek health care for self, with civilians reporting a significantly higher prevalence (35 [32.4\%]) than did military respondents (20 [15.4\%]) $(P=0.002)$. The military respondents were clearly at a higher risk of experiencing all the variants of emotional violence than the civilians $(P=0.00)$. The commonest form of physical violence against women was "being slapped or having something thrown at them, that could hurt", which was markedly higher in the military (43 [33.1\%]) than in the civilian population (10 [9.3\%]), $(P<0.05)$.

Conclusion: IPV is a significant public health problem in Abuja, and the military population is clearly at a higher risk of experiencing all forms of IPV compared to the civilian population. The military should encourage and finance research on effect of military operations and posttraumatic stress disorders on family relationships with a view of developing evidence-based treatment models for military personnel.

Keywords: intimate partner violence, prevalence, military, civilian, women, Abuja, Nigeria

\section{Introduction}

Intimate partner violence (IPV) occurs across the world, in various cultures, ${ }^{1}$ and affects people across societies irrespective of economic status ${ }^{2}$ or gender. ${ }^{3}$ Most data on IPV before World Health Organization multicountry study (WHOMCS) ${ }^{4}$ usually came from the police, clinical settings, nongovernmental organizations, and surveys. This issue 
was one of the reasons for the WHOMCS to standardize the instrument for IPV data collection to allow for comparison across the various settings.

WHOMCS ${ }^{4}$ showed that IPV is widespread in all of the countries covered by the study; however, there was wide variation from country to country and from setting to setting within the same country. The proportion of ever-partnered women who ever experienced physical or sexual violence or both by an intimate partner in their lifetime ranged from $15 \%$ to $71 \%$, with most sites falling between $29 \%$ and $62 \%$. Women in Japan were the least likely to have ever experienced physical or sexual violence or both by an intimate partner, while the greatest amount of violence was reported by women living in provincial (for the most part rural) settings in Bangladesh, Ethiopia, Peru, and the United Republic of Tanzania. For partner violence in the past year, the figures ranged from 4\% in Japan and Serbia and Montenegro to 54\% in Ethiopia. ${ }^{5}$ Since the initiation of the WHO study, other international research initiatives have also used populationbased surveys to estimate the prevalence of violence against women across countries and cultures. These studies provide comparisons with the WHO study and, taken together, now give a more comprehensive picture of violence against women around the world.

In southeast Nigeria, a study conducted among women of childbearing age in a primary health care center reported that over $40 \%$ of them experienced violence in the 12 months prior to the study, ${ }^{6}$ and $87 \%$ of women reported lifetime prevalence of IPV among a migrant community in a community-based survey in southwest Nigeria. ${ }^{7}$ A recent, widely celebrated case that occurred in Akure, Ondo State in Nigeria, was one of IPV involving a royal monarch on grounds of accusation of infidelity against one of his wives in which the monarch not only battered the wife but also went to the extent of going to set her maiden family residence ablaze. ${ }^{8}$

All forms of domestic abuse have one purpose: to gain control over the victim. Abusers use many tactics to exert power over their spouse or partner: dominance, humiliation, isolation, threats, intimidation, denial, and blame. Types of violence, motives of perpetrators, and the social and cultural context are important information that will help in effective intervention, program planning, and implementation. The WHO multicountry study described IPV experienced by women as acts of physical, emotional, or sexual abuse and controlling behaviors by a current or former intimate male partner, whether cohabiting or not. ${ }^{4}$

Physical violence involves contact intended to cause feelings of intimidation, pain, injury, or other physical suffering or bodily harm. Physical abuse includes hitting, slapping, punching, choking, pushing, and other types of contact that result in physical injury to the victim. Physical abuse can also include behaviors such as denying the victim of medical care when needed, depriving the victim of sleep or other functions necessary to live, or forcing the victim to engage in drug/alcohol use against her will. ${ }^{9}$ It can also include inflicting physical injury on other targets, such as children or pets, in order to cause psychological harm to the victim. ${ }^{10}$ Sexual violence is said to occur in any situation in which force is used to obtain participation in unwanted sexual activity; that is, a woman is compelled against her wish to have sexual intercourse or do something sensual that she finds degrading or humiliating. ${ }^{4}$ Forced sex, even by a spouse or intimate partner with whom consensual sex had occurred, is an act of aggression and violence. IPV during pregnancy has grievous health consequences for both the victim and the unborn child. Domestic violence during pregnancy can be missed by medical professionals because it often presents in nonspecific ways. ${ }^{11,12}$

Emotional IPV, also known as psychological or mental abuse, is defined as any behavior that threatens, intimidates, or undermines the victim's self-worth or self-esteem or controls the victim's freedom. ${ }^{13}$ This includes threatening the victim with injury or harm, telling the victim that she will be killed if she ever leaves the relationship and public or private humiliation. Constant criticism, name-calling, and making statements that damage the victim's self-esteem are also common forms of emotional abuse, as is deliberately doing something to make the victim feel diminished or embarrassed. Verbal abuse by an intimate partner is a form of abusive behavior involving the use of language. It is a form of profanity that occurs with or without the use of expletives. Abusers may ignore, ridicule, disrespect, or criticize their victims consistently; they may manipulate words or purposefully humiliate, falsely accuse, or manipulate their victim to submit to undesirable behaviors. They may also make their victims feel unwanted and unloved, threaten them economically, and many a time place the blame and cause of the abuse on the victims. Verbal abuse may involve isolating victims from support systems, harassing them, or demonstrating sudden rages or behavioral changes during which a "face" is shown to victims that is very different from the one portrayed to the outside world. Although oral communication is the most common form of verbal abuse, it also includes abusive words in written form. ${ }^{14}$

Economic abuse by an intimate partner occurs when the abuser has control over the victim's money and other 
economic resources. It is common for the victim to receive less and less money as the abuse continues. This also includes (but is not limited to) preventing the victim from finishing her education or obtaining employment or intentionally squandering or misusing communal resources. ${ }^{14}$ Controlling behavior by an intimate partner was defined by the WHO study as keeping the female partner from seeing friends, restricting contact with her family of birth, insisting on knowing where she is at all times, ignoring or treating her indifferently, getting angry if she speaks with other men and often accusing her of being unfaithful, and controlling her access to health care. ${ }^{4}$

IPV is a new and evolving area of research, particularly in Nigeria, and as such there is a dearth of literature, especially on community-based studies. The authors did not come across any study in the military population in Nigeria. So establishing the different types of IPV from this study will contribute to the existing body of knowledge and may serve as a baseline for future studies in military populations. It may also serve as an advocacy tool for increased sensitization and response to IPV against women, especially in the military population, and to develop alleviation programs. The nature of the military profession is likely to impact uniquely on the way military personnel relate with and treat their female intimate partners when compared to their civilian counterparts. A lot has been studied about IPV in civilian populations, and in this study, the findings can serve as control to form the basis for a comparative analysis aimed at better appreciating the magnitude of the problem in a military community.

The objective of this study was to compare the prevalence of the different types of IPV against women in military and civilian communities in Abuja, Nigeria.

\section{Methodology Background and study design}

The Federal Capital Territory (FCT), Abuja, is made up of six area councils, namely, Abuja Municipal Area Council (AMAC), Abaji, Bwari, Kuje, Kwali, and Gwagwalada.

AMAC is in phase 1 of the city plan, which includes both civilian and military settlements. Some of them include the Lungi military barrack and civilian Zone 2, Wuse.

The study design was a comparative, cross-sectional survey and the study population was composed of females who were in intimate relationship with the male heads of the households in the Lungi military barrack and civilian community Zone 2, Wuse. Inclusion criteria were female intimate partners of the head of the households, who were either married and living together for at least 6 months or unmarried but cohabiting for at least 6 months. So women of all ages who met these criteria were included in the study. Exclusion criteria were female military personnel who were married to civilians and households where both partners were civilians (although living in the barrack). Widows were also excluded in both military and civilian populations.

The minimum sample size formula for comparison of two independent group proportions was used..$^{15}$ Making use of data on the proportion of women who experienced physical violence in a study in a civilian community in $\operatorname{Lagos}^{16}$ and the proportion of women who experienced physical abuse in a military population in USA, ${ }^{17}$ a minimum sample size of 218 for both groups was derived for this study.

AMAC was selected purposely out of the six area councils that make up the FCT because it has a concentration of six barracks. Lungi Barrack was selected out of the six barracks by a simple cluster random sampling using the ballot method, while Zone 2, Wuse, was purposely selected because it appeared to be the closest in features to the barracks in terms of architectural design and ethnic and religious diversity and the fact that majority of the residents are civil servants of various cadres; the area is a distance of about 8-10 km away from the barrack location.

A multistage sampling technique employing probability sampling methods (balloting, stratified, and systematic) in the various stages was used to select a sample of 130 female respondents from each of the study populations (Lungi Barrack and Zone 2, Wuse), ie, 260 respondents. This ensured representativeness of data that was subsequently collected.

\section{Sampling from military community (Lungi Barrack)}

Stage 1 - The accommodation in the barrack was already stratified into commissioned officers and noncommissioned soldiers quarters (known as other ranks). Six blocks were selected out of the existing 18 blocks for "other ranks" by a simple ballot method, and the only block for officers was selected.

Stage 2 - A sampling frame was created for the seven blocks selected using the flat numbering. A total of 266 flats were listed, and a systematic sampling technique was used to select 130 flats using a sampling interval of 2 . Households occupying the selected flats constituted the sampling units.

Stage 3 - An eligible woman who is the intimate partner of the male head of the household in each selected flat was interviewed. Where there were more than one household occupying a flat, only one household (selected by simple balloting) was taken, and in polygamous households, only one female partner (selected by balloting) was interviewed. 
Sampling from civilian community (Zone 2, Wuse)

Stage 1 - Wuse Zone 2 is made up of 16 streets: 9 long streets with an average of 44 houses per street and 7 short streets with an average of 23 houses per street. The streets were stratified into short and long streets, and four streets were selected by simple balloting from each stratum, giving a total of eight streets selected $(4 \times 23=92,44 \times 4=176$; total $92+176=268$ houses).

Stage 2 - A sampling frame was created for each of the selected streets using the house numbering. Where there are blocks of flats, each flat was listed as a house. A total of 268 houses were listed from all the selected streets. A systematic sampling technique was used to select 130 houses from all the selected streets using a sampling interval of 2 . Households occupying the selected houses constituted the sampling units.

Stage 3 - One eligible intimate partner of a household head was interviewed in each household where there was more than one household occupying a house, and only one household was selected by simple balloting; and in polygamous households, only one female partner selected by simple balloting was interviewed.

\section{Data collection and technique}

A semistructured, pretested, interviewer-administered questionnaire was used to collect quantitative data. The questionnaire was adapted from the WHO standardized questionnaire for collection of data on women's health and domestic violence used for the multicountry study on women's health and life experience. The questionnaire consisted of 3 sections: Section 1 was on the sociodemographics of the respondents; Section 2 was on the characteristics of the respondent's current or most recent partner; and Section 3 was on forms of IPV. The four types of IPV were listed and the respondents interviewed about which one had ever applied to them. The questionnaire was pretested in Sanni Abacha Barracks and Zone 1, Wuse, immediately after the training of research assistants and thereafter corrected to remove areas of ambiguity before the data collection. The pretesting helped to assess whether respondents were able and willing to provide the needed information.

The data collection took place between May and June 2012, and completed questionnaires were reviewed by the research assistants and errors and wrong entries corrected before leaving each venue. Completed questionnaires were stored in locked-up bags to further ensure confidentiality.

Data analysis was done using SPSS and Epi-info 2012. Frequencies, proportions, and percentages were generated, and continuous variables were expressed as means $( \pm$ standard deviations).

The prevalence of the different types of IPV in the military and civilian populations was presented on a chart. The association between the different forms of IPV and the respondents' sociodemographic and partner characteristics in the two study populations were compared in tables using percentages and Pearson $\chi$-square statistics, and the $P$-value was assumed to be significant at $\leq 0.05$. Fischer's exact $\chi$-square test was used wherever the cell content was less than 5 .

\section{Ethical approval}

Ethical approval was obtained from the Research and Ethics Committee of Lagos University Teaching Hospital, IdiAraba, and FCT Authority (Health and Human Development Department Ethics Committee). Approval was obtained from both the bodies before commencement of study. Written permission was obtained from the commanding officer of the 7 Guards Battalion, Lungi Barracks. Written informed consent was also obtained from each respondent prior to the interview. Verbal consent was obtained from the chairmen of the streets selected for the study before entry into the civilian community.

\section{Limitations of study}

The security problem ("Boko Haram scare") in Abuja presented a challenge both in the barrack and in the civilian communities in gaining access into people's homes. To overcome this health workers who were involved in the house-to-house distribution of insecticide-treated mosquito nets/polio immunization in FCT were used to facilitate easy access into homes in the study communities.

\section{Results}

Out of a total of 260 respondents selected to be interviewed, $238(91.5 \%)$ completed the interview (130 [100.0\%] in the military and 108 [83.1\%] in the civilian population, giving a total response rate of 238 [91.5\%]). The civilian population in this study was generally older, with a mean age of $38.0 \pm 10.6$ years, compared to $30.4 \pm 10.8$ years in the military population $(P=0.00)$. Majority of the women in both the military and civilian populations were married, but respondents in the civilian community were better educated -67 $(62.0 \%)$ had tertiary education compared to $30(23.1 \%)$ in the military population $(P=0.000)$. Mean ages for civilian and military partners were $44.9 \pm 9.6$ and $37.75 \pm 5.90$, respectively $(P=0.00)$.

Figure 1 shows that the prevalence of the four major types of IPV was consistently higher among the military 


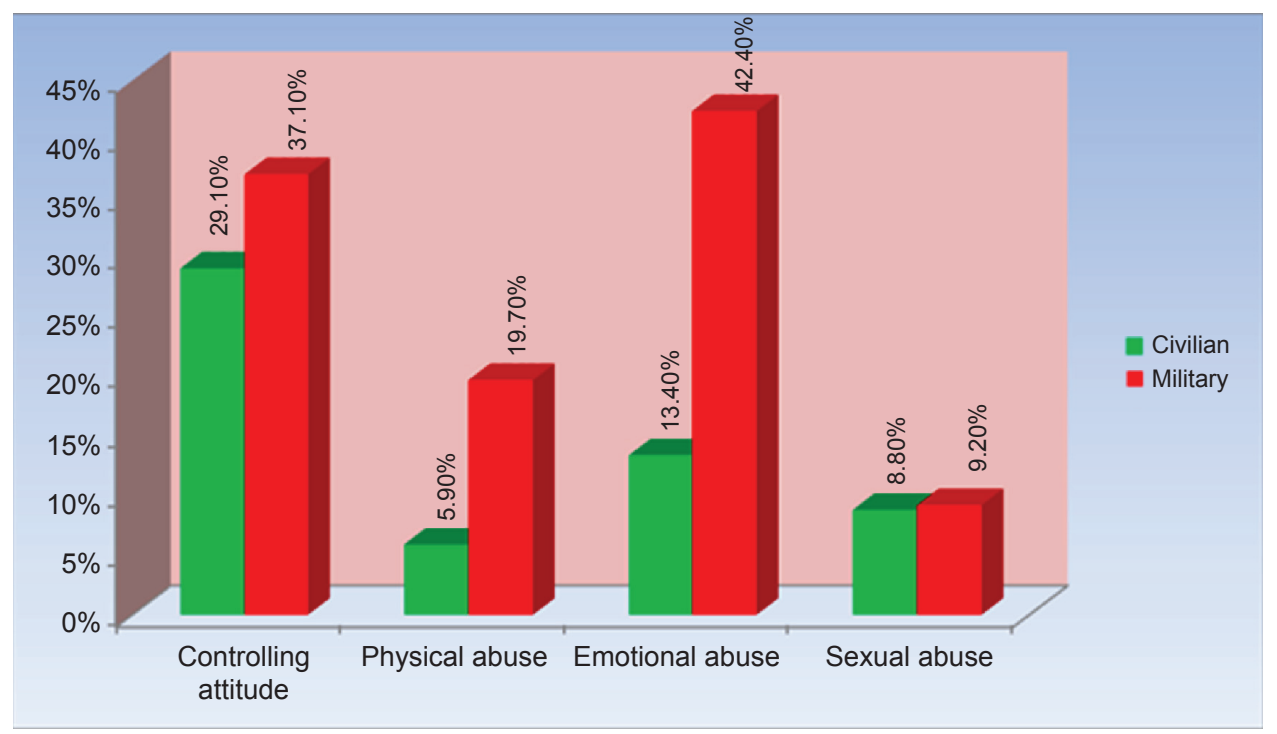

Figure I Reported prevalence of types of intimate partner violence (IPV) among women in military and civilian populations.

Notes: The significant difference between types of IPV prevalence in the two groups: controlling attitude: $z=I .3, P=0.1$; physical abuse: $z=6.8, P=0.000 \mid * ;$ emotional abuse: $z=5.3, P=0.001 *$; sexual abuse: $z=0.16, P=0.44$. $*$ Statistically significant.

respondents than among the civilian respondents: controlling behavior, $37.1 \%$ versus $29.1 \%(P=0.1)$; emotional/ psychological abuse, $42.4 \%$ versus $13.4 \%(P=0.0001)$; physical abuse, $19.7 \%$ versus $5.9 \%(P=0.001)$; and sexual abuse, $9.2 \%$ against $8.8 \%(P=0.44)$, respectively.

Table 1 shows that the commonest form of controlling behavior experienced by respondents in both civilian and military locations was the male partner insisting on knowing where the female partner is at all times, military $69(53.1 \%)$ versus civilians 46 (42.6\%), but the difference is not significant $(P=0.107)$. Except for trying to restrict the partner's contact with the family of birth, $16(14.8 \%)$ among civilians versus $11(8.5 \%)$ among military, respondents in the military experienced all other forms of controlling behavior more

Table I Comparison of self-reported experience of forms of controlling behavior by respondents in civilian and military populations

\begin{tabular}{|c|c|c|c|c|c|}
\hline Forms of controlling behavior & $\begin{array}{l}\text { Civilian community } \\
N=108, n(\%)\end{array}$ & $\begin{array}{l}\text { Military community } \\
N=130, n(\%)\end{array}$ & $\begin{array}{l}\text { Total N=238, } \\
\text { n (\%) }\end{array}$ & Statistics $\chi^{2}$ & $P$-value \\
\hline \multicolumn{6}{|c|}{ Often insist on knowing where you are at all times } \\
\hline Yes & $46(42.6)$ & $69(53.1)$ & II $5(48.3)$ & 2.60 & 0.107 \\
\hline No & $62(57.4)$ & $61(46.9)$ & $123(5 \mid .7)$ & & \\
\hline \multicolumn{6}{|c|}{ Ever kept you from seeing your friends } \\
\hline Yes & $21(19.4)$ & $59(45.4)$ & $80(33.6)$ & 17.79 & $0.000 *$ \\
\hline No & $87(80.6)$ & $71(54.6)$ & $158(66.4)$ & & \\
\hline \multicolumn{6}{|l|}{ Expected you to seek his permission } \\
\hline \multicolumn{6}{|l|}{ to access health care for yourself } \\
\hline Yes & $35(32.4)$ & $20(15.4)$ & $55(23.1)$ & 9.62 & $0.002 *$ \\
\hline No & $73(67.6)$ & $110(84.6)$ & $183(76.9)$ & & \\
\hline \multicolumn{6}{|c|}{ Often gets angry if you speak with another man } \\
\hline Yes & 17 (I5.7) & $34(26.2)$ & $51(21.4)$ & 3.80 & 0.051 \\
\hline No & $91(84.3)$ & $96(73.82)$ & $187(78.6)$ & & \\
\hline \multicolumn{6}{|c|}{ Often suspicious that you are unfaithful } \\
\hline Yes & $16(14.8)$ & $29(22.3)$ & $45(18.9)$ & 2.16 & 0.142 \\
\hline No & $92(85.2)$ & I0I (77.7) & $193(8 I .1)$ & & \\
\hline \multicolumn{6}{|c|}{ Often ignores and treats you indifferently } \\
\hline Yes & $12(I 1.1)$ & $26(20.0)$ & $38(16.0)$ & 3.47 & 0.062 \\
\hline No & $96(88.9)$ & $104(80.0)$ & $200(84.0)$ & & \\
\hline \multicolumn{6}{|c|}{ Ever tried to restrict your contact with family of birth } \\
\hline Yes & $16(14.8)$ & II (8.5) & $27(\mid I .3)$ & 2.37 & 0.124 \\
\hline No & $92(85.2)$ & $119(91.5)$ & $211(88.7)$ & & \\
\hline
\end{tabular}

Note: *Statistically significant. 
Table 2 Comparison of self-reported experience of forms of emotional/psychological violence by respondents

\begin{tabular}{|c|c|c|c|c|c|}
\hline Forms of emotional violence & $\begin{array}{l}\text { Civilian community } \\
\mathrm{N}=108, \mathrm{n}(\%)\end{array}$ & $\begin{array}{l}\text { Military community } \\
N=130, n(\%)\end{array}$ & $\begin{array}{l}\text { Total } N=238 \text {, } \\
\text { n (\%) }\end{array}$ & $\begin{array}{l}\text { Statistics } \\
\chi^{2}\end{array}$ & $P$-value \\
\hline \multicolumn{6}{|c|}{ Ever insulted you or made you feel bad about yourself } \\
\hline Yes & $28(25.9)$ & $95(73.1)$ & $123(5 \mid .7)$ & 52.52 & $0.000 *$ \\
\hline No & $80(74.1)$ & $35(26.9)$ & $115(48.3)$ & & \\
\hline \multicolumn{6}{|c|}{ Ever done things to scare or intimidate you on purpose } \\
\hline Yes & $15(13.9)$ & $26(20.0)$ & $41(17.2)$ & 1.55 & 0.214 \\
\hline No & $93(86.1)$ & $104(80.0)$ & $197(82.8)$ & & \\
\hline \multicolumn{6}{|c|}{ Ever belittled or humiliated you in front of other people } \\
\hline Yes & $16(14.8)$ & $20(15.4)$ & $36(15.1)$ & 0.01 & 0.902 \\
\hline No & $92(85.2)$ & $110(84.6)$ & $202(84.9)$ & & \\
\hline \multicolumn{6}{|c|}{ Ever threatened to hurt you or someone you love } \\
\hline Yes & II (I0.2) & $13(10.0)$ & $24(10.1)$ & 0.00 & 0.962 \\
\hline No & $97(89.8)$ & $117(90.0)$ & $214(89.9)$ & & \\
\hline
\end{tabular}

Note: *Statistically significant.

than did the civilians. Significantly more respondents from the military population (59 [45.4\%]), compared to civilians (21 [19.4\%]), were prevented by their partners from seeing their friends $(P=0.000)$. The situation was opposite with regard to permission to seek health care for self: significantly more civilian respondents (35 [32.4\%]) experienced this compared to the military respondents (20 [15.4\%]), $P=0.002$.

The commonest form of emotional violence in both the settings is the respondent being insulted or being made to feel bad about herself by the male partner (Table 2). Over $70 \%$ of the respondents in the military were victims of this variant of emotional violence, which was significantly higher than that seen among the civilian respondents (28 [25.9\%]), $(P=0.000)$.
Table 3 indicates that all the variants of physical violence were experienced more by women in the military population than by the civilians. The commonest form of physical violence against women was "being slapped or had something thrown at them, that could hurt", the prevalence of which is significantly higher in the military (43 [33.1\%]) than in the civilian population $(10[9.3 \%]),(P<0.05)$.

The prevalence of physical violence during pregnancy among the respondents is shown in Table 4. Seventeen $(13.1 \%)$ of the respondents in the military population were hit or beaten by their partners in the last pregnancy, compared to $8(7.4 \%)$ in the civilian population. Also, slightly more respondents in the military (5 [3.8\%]), compared to civilians

Table 3 Comparison of self-reported experience of forms of physical violence by respondents in civilian and military populations

\begin{tabular}{|c|c|c|c|c|c|}
\hline $\begin{array}{l}\text { Forms of physical } \\
\text { violence }\end{array}$ & $\begin{array}{l}\text { Civilian community } \\
N=108, \mathrm{n}(\%)\end{array}$ & $\begin{array}{l}\text { Military community } \\
\mathrm{N}=\mid 30, \mathrm{n}(\%)\end{array}$ & $\begin{array}{l}\text { Total } N=238, \\
\text { n (\%) }\end{array}$ & Statistics $\chi^{2}$ & $P$-value \\
\hline \multicolumn{6}{|c|}{$\begin{array}{l}\text { Ever been slapped or had something thrown } \\
\text { at you, that could hurt }\end{array}$} \\
\hline Yes & $10(9.3)$ & $43(33.1)$ & $53(22.3)$ & 19.33 & $0.000^{*}$ \\
\hline No & $98(90.7)$ & $87(66.9)$ & $185(77.7)$ & & \\
\hline \multicolumn{6}{|c|}{ Ever been kicked, dragged, or beaten up } \\
\hline Yes & $6(5.6)$ & $24(18.8)$ & $30(12.6)$ & 8.92 & $0.003^{*}$ \\
\hline No & $102(94.4)$ & $106(81.2)$ & $208(87.4)$ & & \\
\hline \multicolumn{6}{|c|}{ Ever been pushed or shoved or pulled by the hair } \\
\hline Yes & $6(5.6)$ & $22(16.9)$ & $29(12.2)$ & 7.34 & $0.007^{*}$ \\
\hline No & $102(94.4)$ & $108(83.1)$ & $210(87.8)$ & & \\
\hline \multicolumn{6}{|c|}{ Ever been hit with his fist or object that can hurt } \\
\hline Yes & $10(9.3)$ & $18(13.8)$ & $28(I 1.8)$ & 1.19 & 0.274 \\
\hline No & $98(90.1)$ & $112(86.2)$ & $210(88.2)$ & & \\
\hline \multicolumn{6}{|c|}{ Ever been threatened with a dangerous weapon } \\
\hline Yes & $4(3.7)$ & $6(4.6)$ & $10(4.2)$ & $0.12 * *$ & 0.727 \\
\hline No & $104(96.3)$ & $124(95.4)$ & $228(95.8)$ & & \\
\hline
\end{tabular}

Notes: *Statistically significant; **Fischer's exact test. 
Table 4 Comparison of self-reported experience of physical violence during the last pregnancy by respondents

\begin{tabular}{|c|c|c|c|c|c|}
\hline Physical violence in pregnancy & $\begin{array}{l}\text { Civilian community } \\
N=108, n(\%)\end{array}$ & $\begin{array}{l}\text { Military community } \\
\mathrm{N}=130, \mathrm{n}(\%)\end{array}$ & $\begin{array}{l}\text { Total } \mathbf{N}=\mathbf{2 3 8} \text {, } \\
\text { n (\%) }\end{array}$ & Statistics $\chi^{2}$ & $P$-value \\
\hline \multicolumn{6}{|l|}{ Ever slapped, hit, or beaten } \\
\hline \multicolumn{6}{|l|}{ by partner in last pregnancy } \\
\hline Yes & $8(7.4)$ & $17(13.1)$ & $25(10.5)$ & $15.94 * *$ & $0.000 *$ \\
\hline No & $87(80.6)$ & $90(69.2)$ & I $77(74.4)$ & & \\
\hline Do not recall & $4(3.7)$ & $\mathrm{I}(0.7)$ & $5(2.1)$ & & \\
\hline Never been pregnant & $9(8.3)$ & $22(17.0)$ & $31(13.0)$ & & \\
\hline \multicolumn{6}{|c|}{ Ever been punched or kicked in the } \\
\hline \multicolumn{6}{|l|}{ abdomen during pregnancy } \\
\hline Yes & $3(2.8)$ & $5(3.8)$ & $8(3.4)$ & $6.28 * *$ & $0.043^{*}$ \\
\hline No & $100(92.6)$ & $121(93.1)$ & $221(92.9)$ & & \\
\hline Do not recall & $5(4.6)$ & $4(3.1)$ & $9(3.8)$ & & \\
\hline
\end{tabular}

Notes: *Statistically significant; **Fischer's exact test.

(3 [2.8\%]), were punched or kicked in the abdomen in their last pregnancy. These differences are statistically significant $(P<0.05)$.

Table 5 shows that women from the military population reported higher prevalence for two out of the three variants of sexual violence than did the civilian population. However, these differences were not statistically significant $(P>0.05)$.

\section{Discussion}

Approximately $40 \%$ of the military population and $30 \%$ of the civilian population experienced controlling behavior in this study. The patriarchal nature of the Nigerian society generally makes the men view and treat women as a piece of their property which they need to exercise control over. This is even more pronounced among military personnel, who are used to regimentation by nature of their training and career and may sometimes find it difficult to draw a line between their job and family relationships. Most studies did not report controlling behavior as a separate entity of IPV. However, WHOMSC ${ }^{4}$ reported that in all sites of the study, the experience of physical or sexual violence or both tends to be associated with one or more controlling behaviors by an intimate partner. WHOMSC ${ }^{4}$ and a study in Iran ${ }^{13}$ reported similar prevalence as was reported in the military population in this study, but these were higher than what was found in the civilian population.

Regarding emotional violence, over $40 \%$ of respondents in the military and less than $15 \%$ in the civilian population reported this experience. The higher prevalence among the military respondents may be due to the fact that they have lower education and earn a lower income. Emotional violence has been found to be associated with low self-worth and low self-esteem. ${ }^{13}$ IPV is said to result from women's subordinate position; therefore, in many cultures, men assume the right to control their wives, including insulting them. ${ }^{18}$ The civilian finding in this study is comparable to the $18 \%$ reported in Egypt, ${ }^{19}$ but lower than findings in all settings in the WHOMSC study, ${ }^{4}$ while the prevalence in the military population was higher than what was reported in some studies in Mexico ${ }^{20}$ and Iran. ${ }^{21}$

This study reported a prevalence of physical violence of $19.7 \%$ and $5.9 \%$ in the military and civilian populations, respectively. The experience of physical violence was more

Table 5 Comparison of self-reported experience of forms of sexual violence by respondents

\begin{tabular}{|c|c|c|c|c|c|}
\hline Forms of sexual violence & $\begin{array}{l}\text { Civilian community } \\
N=108, \text { n (\%) }\end{array}$ & $\begin{array}{l}\text { Military community } \\
\mathrm{N}=\mid 30, \mathrm{n}(\%)\end{array}$ & $\begin{array}{l}\text { Total } N=238, \\
\text { n (\%) }\end{array}$ & Statistics $\chi^{2}$ & $P$-value \\
\hline \multicolumn{6}{|c|}{ Ever forced to have sex against will } \\
\hline Yes & $21(19.4)$ & $24(18.5)$ & $45(18.9)$ & 0.86 & 0.650 \\
\hline No & $87(80.6)$ & $106(81.5)$ & $193(8 I . I)$ & & \\
\hline \multicolumn{6}{|c|}{ Ever had sex out of fear of partner aggression } \\
\hline Yes & $19(17.6)$ & $25(19.2)$ & $44(18.5)$ & 0.00 & 0.98 \\
\hline No & $89(82.4)$ & $105(80.8)$ & $194(81.5)$ & & \\
\hline \multicolumn{6}{|c|}{ Ever forced into degrading sexual act } \\
\hline Yes & $6(5.6)$ & $10(7.7)$ & $16(6.7)$ & 0.43 & 0.513 \\
\hline No & $102(94.4)$ & $120(92.3)$ & $222(93.3)$ & & \\
\hline
\end{tabular}


than three times higher in the military population than in the civilian population. This could be due to higher stress levels associated with a military career such as frequent separation, long work hours, dangerous working environment, and the intense nature of the military training. Certain military culture and lifestyle have a strong hand in shaping their experiences, as well as making the female partners extremely vulnerable to the consequences of partner abuse. ${ }^{22}$ In addition to the unique vulnerability of female partners of military personnel to experience IPV, the military lifestyle is also of special concern due to the potential negative consequences of the accumulation of the isolation, secretiveness, and dependability on their career. For many military members, being in the military is more than just a career; it is their identity. ${ }^{23}$ For example, if it is found out that a military personnel has committed an act of violence against a family member, the personnel may face a dishonorable discharge from the military, consequently losing his military title, employment, and family income. The loss of this identity can lead to higher risks of violence because the abuser may feel as though he has nothing left to lose now that he has lost his identity and career. ${ }^{23}$ Thus, the nature of the military profession is likely to impact negatively on the way they relate with and treat their female intimate partners when compared to their civilian counterparts.

Furthermore, a higher proportion of the respondents' partners consumed alcohol and took psychoactive drugs, and both of these features have been found to be comorbid with physical violence. ${ }^{24}$ This finding is consistent with that of a US study in military/civilian populations that reported a $2-5$ times higher prevalence in favor of military population. ${ }^{25}$ In some other studies, it was found that the experience of physical violence is the most prevalent form of violence within the military when the male was the individual in the military. ${ }^{26,27}$ In this study, physical violence was found to be the third highest after emotional violence and controlling behavior. This is at variance with the finding from a military-civilian comparative study in the USA that found physical violence to account for over $90 \%$ of all substantiated cases of partner violence in military families, followed by emotional violence, neglect, and sexual abuse. ${ }^{28}$ The prevalence of physical violence reported by the military and civilian populations in this study was lower than what was reported by most sites in the $\mathrm{WHOMCS}^{4}$ study, which ranged from $13 \%$ in Japan to $61 \%$ in Peru province, then $40 \%$ in Bangladesh ${ }^{29}$ the same also applies in some studies in Nigeria. $6,7,16,27$

This study reported a low prevalence of sexual violence in the military $(9.2 \%)$ and civilian $(8.8 \%)$ populations, showing minimal difference between the two groups. This could be because sex is considered a very personal issue in the Nigerian context that people do not discuss it freely. Data on prevalence of sexual violence obtained in both the military and civilian populations are comparable to between $6 \%$ and $10 \%$ in Japan, Serbia and Montenegro but lower than in Ethiopia province, Bangladesh province, and Thailand city in the WHOMCS. ${ }^{4}$ Higher figures were reported in Canada, ${ }^{30,31}$ and lower prevalence was reported in Egypt. ${ }^{19}$ Forced or coerced sexual activity was the commonest form of sexual violence documented in this study. This has implications for a variety of health consequences, which include inability to care for their reproductive health, psychological problems, sexual dysfunctions, low self-esteem, suicide ideation, and sexual risk-taking. ${ }^{32}$

In conclusion, IPV constitutes a significant public health problem in Abuja, and the military population is clearly at a higher risk of experiencing all forms of IPV compared to the civilian population. Addressing IPV should be multisectorial (involving individuals, family, community, health, social services, religious organizations, judiciary and police, trade unions, businesses, and media) and requires immediate and long-term commitment and strategies.

Beyond this, the military should also encourage and finance research in the area of studying the effects of military operations and posttraumatic stress disorders on family relationships with a view to developing evidence-based treatment models for military personnel.

It is suggested that for future research, long-term interventional studies may be designed to ascertain the effect of family reorientation measures on the prevalence of the various types of IPV in Nigerian families.

\section{Disclosure}

The authors report no conflicts of interest in this work.

\section{References}

1. World Health Organization. A Priority Health Issue [WHO/FRH/ WHD/97.8]. Geneva, Switzerland: World Health Organization; 1997.

2. Nicholas TL, Hamel J. Family Interventions in Domestic Violence: A Handbook of Gender Inclusive Theory and Treatment. New York, NY: Springer Publishing; 2007:5-6.

3. Harrison D. The First Casualty: Violence against Women in Canadian Military Communities. Toronto, ON: James Lorimer \& Company Ltd; 2002.

4. World Health Organization. WHO Multi-country Study on Women's Health and Domestic Violence against Women: Initial Results on Prevalence, Health Outcomes and Women's Responses. Geneva, Switzerland: World Health Organization; 2005.

5. United Nations General Assembly. Declaration on the elimination of violence against women. In: Proceedings of the 85th Plenary Meeting; December 20, 1993; Geneva, Switzerland. 
6. Ilika AL, Okonkwo PI, Adogu P. Intimate partner violence among women of childbearing age in a primary health care centre in Eastern Nigeria. Afr J Reprod Health. 2002;6(3):53-58.

7. Owoaje ET, Olaolorun FM. Intimate partner violence among women in a migrant community in southwest Nigeria. Int $Q$ Community Health Educ. 2005-2006;25(4):337-349.

8. National Life Newspaper Nigeria. Friday November 11, 2010; front page.

9. US Department of Justice. About Domestic Violence 2007. Washington, DC: US Department of Justice.

10. Jewkes R, Levin J, Penn-Kekana L. Risk factors for domestic violence: findings from a South African cross-sectional study. Soc Sci Med. 2002;55(9):1603-1617.

11. Johnson JK, Haider F. The prevalence of domestic violence in pregnant women. BJPG. 2003;110(3):272-275.

12. Huth-Bocks AC, Levendosky AA, Boyat GA. The effects of domestic violence during pregnancy in maternal and infant health. Violence Vict. 2002;17(2):169-185.

13. Nojomi M, Agaee S, Eslami S. Domestic violence against women attending gynecologic outpatient clinic. Arch Iran Med. 2007;10(3): 309-315.

14. Yoshihama M, Sorenson SB. Physical, sexual and emotional abuse by male intimates, experience of women in Japan. Violence Vict. 1994; 9:63-77.

15. Abby A, Ross LT, McDuffie D. Alcohol's role in sexual assault. In: Watson RR, editor. Drug and Alcohol Reviews: Vol. 5. Additive Behaviours in Women. Totowa, NJ: Human Press; 1995:3-25.

16. Odujurin O. Wife battering in Nigeria. Int J Gynaecol Obstet. 1999; 41(2):159-164.

17. Rentz ED, Martin SL, Gibbs DA, Clinton-Sherrod M, Hardison J, Marshall SW. Family violence in the military: a review of the literature. Trauma Violence Abuse. 2006;7:93-108.

18. Bachman R, Altzman ES. Violence against Women: Estimates from the Redesigned Survey (PDF NCJ1543-48). Washington, DC: Bureau of Justice Statistics; August 1995. Available from: http://www.ojpusdoj. gv/bjs/pub/pdf/femvied.pdf. Accessed March 23, 2012.

19. Egypt National Demographic and Health Survey, 2005. Available from: http://dhsprogram.com/pubs/pdf/FR176/FR176.pdf. Accessed 11 February 2015.
20. Olaiz G, Rojas R, Valdez R, Franco A, Palma O. Prevalencia de diferentes tipos de violencia en usuarias del sector salud en México [Gender violence prevalence in female users of health services in Mexico]. Salud Publica Mex. 2006;48(Suppl 2):S232-S238. Spanish.

21. Ghazizadeh A. Domestic violence: a cross-sectional study in an Iranian city. East Mediterr Health J. 2005;11(5-6):880-887.

22. Harrison D. The First Casualty: Violence against Women in Canadian Military Communities. James Lorimer \& Company Ltd: Toronto, ON; 2002.

23. Stamm S. Intimate partner violence in the military: securing our country, starting with the home. Family Court Rev J. 2009;47(2):321-339.

24. Family Violence Prevention Fund. Facts Sheet: Intimate Partner Violence and Healthy People, End Abuse. San Francisco, CA: Family Violence Prevention Fund; 2010.

25. Heyman RE, Neidig PH. A comparison of spousal aggression prevalence rates in U.S. army and civilian representative samples. J Consult Clin Psychol. 1999;67(2):239-242.

26. Forgey M, Badger L. Patterns of intimate partner violence among married women in the military: type, level, directionality and consequences. J Family Violence. 2006;21:369-380.

27. Fawole OI, Aderomnu AL, Fawole AO. Intimate partner abuse: wife beating among civil servants in Ibadan, Nigeria. Afr J Reprod Health. 2005;9(2):54-64.

28. Rentz ED, Martin SL, Gibbs DA, Clinton-Sherrod M, Hardson J, Marshall SW. Family violence in the military: a review of the literature. Ann Am Acad Political Social Sci. 2011;638:163-183.

29. Bates LM, Schuler SR, Islam F, Islam K. Socioeconomic factors and processes associated with domestic violence in rural Bangladesh. Int Fam Plan Perspect. 2009;(4):190-199.

30. Randall M, Haskell L. Sexual violence in women's lives: findings from the women's safety project, a community based survey. Violence Against Women. 2005;1(1):6-31.

31. Ruiz-Perez I, Mata-Pariente N, Plazaola-Castano J. Women's response on intimate partner violence. J Interpers Violence. 2006;21(9): $1156-1168$

32. Heise LL, Ellsberg M, Gottemoller M. Ending Violence against Women Baltimore, MD: Center for Communications Programs, John Hopkins University School of Public Health. Population Reports Series. 2002; 11(27):1-7.
International Journal of Women's Health

\section{Publish your work in this journal}

The International Journal of Women's Health is an international, peerreviewed open-access journal publishing original research, reports, editorials, reviews and commentaries on all aspects of women's healthcare including gynecology, obstetrics, and breast cancer. The manuscript management system is completely online and includes

\section{Dovepress}

a very quick and fair peer-review system, which is all easy to use. Visit http://www.dovepress.com/testimonials.php to read real quotes from published authors. 